\title{
Educação como expressão do corpo que dança: um olhar sobre a vivência da dança em projetos sociais
}

\section{Education as an expression of the body that dances in social projects}

\author{
Thays Anyelle Macêdo da Silva Ramos* \\ Rosie Medeiros*
}

\begin{abstract}
RESUMO
Este artigo apresenta como objetivo investigar a dança enquanto fonte educativa, a partir de uma experiência desenvolvida no Projeto social, da UFRN denominado Nova Descoberta (PND). Para tanto a investigação partiu da questão o que é dança para você, comparando as respostas iniciais e finais, após a vivência contextualizada da mesma, por alunos da faixa etária entre 07 e 17 anos. Como referência metodológica, utilizamos da fenomenologia de Merleau-Ponty, que evidencia a experiência vivida como fonte de conhecimento, considerando enquanto técnica de pesquisa a descrição, a redução e a interpretação/compreensão do fenômeno, que foram lançados ao PND, o que permitiu revelarmos horizontes educativos no ato de conhecer e vivenciar a dança.
\end{abstract}

Palavras-chave: Dança. Educação. Projetos sociais.

\begin{abstract}
This article aims to investigate the dance as an educational source, based on an experience developed in the UFRN's social project called Nova Descoberta (PND). In order to do so, the investigation started from the question what is dance for you, comparing the initial and final answers, after the contextualized experience of the same, by students of the age group

* Universidade Federal do Rio Grande do Norte. Centro de Ciências da Saúde. Natal, Rio Grande do Norte, Brasil. E-mail: thays_anyelle@yahoo.com.br. ORCID: https://orcid.org/00000001-6448-7135. E-mail: marie.medeiros@gmail.com. ORCID: https://orcid.org/0000-0003-
\end{abstract} 3984-0720 
between 7 and 17 years. As a methodological reference, we used MerleauPonty's phenomenology, which evidences the lived experience as a source of knowledge, considering as a research technique the description, reduction and interpretation / understanding of the phenomenon, which were released to the PND, which allowed us to reveal Educational horizons in the act of knowing and experiencing dance.

Keywords: Dance. Education. Social projects.

\section{Apresentação: indo além de passos?}

O presente artigo apresenta como objetivo refletir sobre a dança enquanto fonte educativa para crianças e adolescentes em projetos sociais, mais especificamente no projeto da Universidade Federal do Rio Grande do Norte, intitulado: Projeto Nova Descoberta (PND), evidenciando que dança é educação (PORPINO, 2006).

O Projeto Nova Descoberta teve seu início em Natal no ano de 2003, a partir de um incentivo do Departamento de Educação Física da Universidade Federal do Rio Grande do Norte, orientado pela solução pedagógica proposta para o desenvolvimento humano, tendo como um dos principais objetivos desenvolver o esporte na dimensão humana e como estratégia na mobilização e formação social dos jovens, incentivando o acesso aos bens culturais.

$\mathrm{O}$ ensino da dança inseriu-se neste contexto de inserção cultural, como oportunidade de vivências diferenciadas, para além do esporte. Esse projeto visava promover educação para crianças e adolescentes de contexto social de risco da grande Natal, dos bairros de Nova Descoberta e Cidade da Esperança.

Ao inserir a dança nesse projeto, percebemos a importância em inserir essas crianças e jovens no universo da cultura e da arte, pois a dança para além da repetição de simples coreografias, constrói uma realidade social, cultural e política, enfim, carrega consigo identidades de povos específicos, e pode ser compreendida como uma linguagem voltada à transformação do homem em benefício da educação.

Não falamos de qualquer conceito de Educação, que se limita a comandos ou aquisição de conhecimentos prontos, mas que abre a possibilidade da interpretação e da criação de sentidos como evidencia Porpino (2006), em suas reflexões sobre a dança e a educação.

Em concordância com Medeiros (2016), acreditamos que a educação acontece em vários espaços e não só nos espaços formais como a sala de aula, 
a escola, as universidades, mas também no espaço da arte e da cultura. Reconhecemos que é uma tarefa da educação a inserção do indivíduo no mundo da cultura e da arte ampliando os modos de ser e de conviver dos indivíduos.

A dança como educação torna-se possível porque o indivíduo reage ao mundo através de seu corpo, e especificamente através do movimento corporal, onde é este que possibilita às pessoas se comunicarem, trabalharem, aprenderem, sentirem o mundo e serem sentidos (STRAZZACAPPA, 2001).

Segundo Porpino (2006), observamos historicamente que a dança vem desenhada como manifestações do corpóreo, do sensível, do estético, tais dimensões que por vezes ainda são pouco consideradas no pensamento educacional do ocidente que prioriza o racional em detrimento do sensível. Mas, em meio a essas controvérsias, a dança vem resistindo e tomando cada vez mais seu espaço na Educação, na Educação Física, em instituições educacionais, assim como, no contexto educativo de projetos sociais como especifica essa pesquisa.

\section{Bastidores da pesquisa: cenário, palco, bailarinos}

Com a pretensão de encontrar um percurso metodológico que viabilizasse o encontro com os objetivos da pesquisa, de apresentar os sentidos educativos da dança no projeto social nova descoberta, apontamos para a atitude fenomenológica de Merleau-Ponty. Em seus estudos o filósofo define um olhar expressivo sobre o corpo, configurando uma linguagem sensível que é expressa nos movimentos, onde aprofunda as teses da Fenomenologia num novo arranjo para o conhecimento enquanto resultado de nossa experiência no mundo vivido (NÓBREGA, 2010).

A Fenomenologia, neste sentido, busca como finalidade compreender o sentido do mundo, ou seja, suas essências. Onde estas essências, encontram-se na existência. Como afirma Medeiros (2016) baseada nas reflexões de MerleauPonty: "nessa relação com o mundo o corpo vai aprendendo os vários sentidos da existência" (MEDEIROS, 2016, p.12).

Nóbrega (1999) define a fenomenologia como sendo:

a atitude de envolvimento com o mundo da experiência vivida, com o intuito de compreendê-la. Esta compreensão não é uma representação mental do mundo, mas, sim, envolvimento que permite a reflexão, a interpretação e a vivência. (NÓBREGA, 1999, p. 35). 
Em relação à noção de mundo, Merleau-Ponty afirma que o mundo é aquilo que vivo e não aquilo que penso. Estamos vulneráveis a este mundo, comunicamo-nos com ele, mas não podemos possuí-lo, pois este é inesgotável. A atitude fenomenológica ultrapassa o racionalismo ao lançar-se no mundo e buscar sempre novos olhares e novos sentidos para a existência, unindo sujeito e o objeto em sua compreensão de mundo e de corpo (MEDEIROS, 2016).

Caminhamos na pesquisa neste cenário fenomenológico que coloca o conhecimento como resultado de nossa experiência no mundo-vivido, sendo essa, uma relação entre nossas experiências com a experiência do outro, e vice-versa, ampliando o olhar investigativo. Para tanto, a fenomenologia utiliza das técnicas de: descrição, redução e interpretação/compreensão do fenômeno investigado.

Neste sentido, lançamos o nosso olhar para o Projeto Nova Descoberta, com o objetivo de desvendar e evidenciar a dança enquanto ação educacional. A princípio descrevemos o projeto, as experiências produzidas e vivenciadas, enquanto docentes do mesmo, no intuito de evidenciar horizontes interpretativos do fenômeno investigado, pois a descrição visa evidenciar os diferentes significados do fenômeno (MARTINS 2005), assim sendo, do projeto Nova descoberta.

Após a descrição, voltamos nosso olhar para a redução, como forma de colocar em suspensão as crenças e explicações prévias do fenômeno, no sentido de buscar o irrefletido (MERLEAU-PONTY, 1999). Assim, suspendemos nossa crença prévia sobre o Projeto nova descoberta, para descortinamos novos sentidos sobre a experiência vivida.

Por fim, apresentamos a interpretação e compreensão do fenômeno, quando criamos enfim sentidos e significados para o fenômeno investigado, nessa pesquisa, são todos os sentidos criados para o Projeto nova descoberta, que apresenta a dança enquanto fonte infinita de educação.

Os palcos para atuação da dança no projeto foram o Ginásio do Campus da UFRN- Universidade Federal do Rio Grande do Norte, contemplando as crianças do bairro de Nova Descoberta, e a Escola Municipal Professora Ivonete Maciel, localizada no bairro de Cidade da Esperança, todos na Cidade do Natal-RN. Para o estudo do fenômeno, relacionado à descrição, redução e interpretação, nos utilizamos duas horas de aula por semana para cada núcleo durante oito meses.

No palco da Cidade da Esperança participaram das aulas 45 alunos, que compõem os bailarinos desta pesquisa, com faixa etária entre 07 a 11 anos. Na UFRN tivemos uma turma com 30 educandos, com faixa etária entre 07 e 17 anos. Vale ressaltar que as turmas foram divididas em subturmas, tendo como referência a aproximação entre as faixas etárias.

No intuito de organizar a técnica de pesquisa, balizada na descrição do fenômeno, redução e interpretação dos resultados, a seguinte questão foi lançada para as turmas, no primeiro e último encontro: “O que é dança para você?”, o que 
possibilitou uma análise sobre o conhecimento produzido a partir da vivência das diferentes expressões, técnicas e estéticas do dançar, ratificando a dança enquanto fonte educativa.

\section{O dito e o interdito da dança}

Em qualquer apreciação artística, no momento em que se abrem as cortinas, encontramos fora o palco, cenário e os artistas ali prontos, um começo de uma obra artística que carrega consigo misturas de sentimentos diversos, expectativas de um público e daqueles artistas. Mesmo na primeira cena as expectativas estão voltadas quase sempre para o desfecho que responda às perguntas nascidas no decorrer da obra. Nem sempre isso acontece. Às vezes o meio é mais interessante e atrativo que o fim, ou mesmo, nada na obra é apreciativo, claro que tudo isto é subjetivo. Mas isso são riscos que o novo, o que se mostra, traz. Tudo que é novo é desconfiável e está ali para ser avaliado e, assim, aceito ou rejeitado. Morin (2001) diz que o inesperado surpreende-nos pelo fato de nos apoiarmos em teorias e ideias já conhecidas e firmadas, que nos impedem de acolher o novo. $\mathrm{O}$ autor continua defendendo que para vislumbrarmos mudanças do nosso modo de ser e agir, precisamos encarar alguns desafios repletos de casos e acasos, ordem e desordem, organização e desorganização, situações essas que não nos é possível determinar quando, onde e com qual intensidade poderão aparecer para resolvermos. Nesta alusão, voltamos nosso olhar investigativo para o Projeto Nova Descoberta como educadoras de dança, para assim buscarmos novos olhares e sentidos para essa vivência.

Abrindo as cortinas dos primeiros encontros com as turmas, tanto no palco do Campus da UFRN, como na Escola Municipal Ivonete Maciel, a primeira cena que se vê é uma educadora sentada em roda com os alunos. Alguns com expressões de surpresa por causa da proposta de se inserir a dança em meio a suas práticas, outros com raiva por ter que dividir o esporte com a dança, outros com expressões de curiosidade querendo saber como se evidenciariam aquelas aulas.

O que é dança para você? Esta foi a pergunta feita naqueles primeiros dias de aula. A intenção era com aquelas respostas buscarmos leituras de significados do dançar para os alunos. As respostas foram registradas na forma escrita e foram trabalhadas oralmente. Numa resistência aparente à dança pela maioria, as respostas nos deram fontes interpretativas sobre os significados trazidos por eles do seu mundo-vivido para aquela sala de aula. Podemos citar entre as respostas apresentadas: 'danço para conquistar as doidinhas', 'dançar é coisa de boiola', 
'danço nos pancadões para zuar e sair batendo', 'não danço', 'danço para me divertir', muitos ' $n a \tilde{o}$ sei' também foram apresentados enquanto respostas. Diante desses primeiros sentidos sobre a dança, foi possível fazer uma leitura da realidade desses alunos, e por meio desses significados do dançar nasceu ali a necessidade de um trabalho de ressignificação desses conhecimentos por ora apresentados.

Acreditamos que mesmo com variadas definições, torna-se uma tarefa árdua tentar conceituar a dança; ela escorrega, evita a conceituação e possui um caráter não verbal, inscreve-se como uma alternativa entre a autodisciplina e o transe, entre o jogar e o trabalhar. Sua lógica é a do acontecimento, ela só acontece no instante, só existe na execução. Assim como afirma Feitosa (2009), "trata-se de uma série de agoras escapantes e repetíveis" (p. 34).

A dança - ou, como pontuou Laban (1978), este "poema do esforço" - é uma forma de manifestação artística e lúdica que guarda uma ligação extremamente íntima com o corpo.

Medeiros (2016), em suas reflexões sobre a arte, tendo como base o pensamento de Merleau-Ponty, a denomina como única, singular, não só para quem aprecia, mas também para o artista que a vivencia, assim, ela não seria uma imitação, mas uma forma de expressar inúmeros significados. A dança como obra de arte abre espaço para diversas leituras e significações e o fazer-se e refazer-se não só no seu corpo que dança, mas também pelo corpo do outro que também dança ou que aprecia. Assim, o corpo quando dança vem dotado de significados próprios que poderão ser captados e vividos pelo outro que aprecia.

Porpino (2006) acrescenta de forma poética que se a dança fosse um texto escrito, poderia ser uma poesia e se fosse um discurso, poderia ser uma declaração de amor à vida, mas como é gesto, a dança é o bailarino em seu movimento. Mesmo diante de muitos significados atribuídos, a dança será apenas no movimento do corpo entendida pelo homem. Tanto para aquele que dança como para o que aprecia, ela faz sentido e inventa novos sentidos. Esses significados entrecruzam e criam outros infinitos.

Segundo Laban (1990), a dança é um dos meios pelos quais todos os povos expressam sua cultura, sua relação com a natureza e com os homens.

Mas quando saímos dos livros, dos discursos acadêmicos, das descrições daqueles que dedicaram tempo estudando o assunto e ganhamos as ruas, quais os significados impregnados na comunidade sobre a dança? Utilizamos nesta pesquisa os termos dito e interdito. O dito seria o que está explícito nos discursos, ou seja, o discurso inicial dos alunos seria o dito, e o que é silenciado das formações discursivas, o que não é dito, seria o interdito (ASSIS et al., 2005). Este termo interdito utilizado neste trabalho representa uma verdade que foi encoberta, silenciada, para que outros significados rasos de reflexão sobre o dançar venham 
se estabelecer. Significados que vêm carregados de conceitos e regras sobre gênero, raça, etnia, classe social, entre outros, que estão/são incorporados durante nosso processo de ensino-aprendizado sem que muitas vezes percebamos aquilo que estamos construindo ou até mesmo (re)produzindo (MARQUES, 1997).

Esses conceitos se difundem pela sociedade como podemos observar de forma clara nos discursos dos alunos do PND, quando alguns afirmam que "dança é coisa de boiola", "é de fresco", dando a ideia de que somente à mulher

é permitido experenciá-la, ou se, por outro lado, for necessário aprender que seja "para conquistar as doidinhas" ou para utilizar "nos pancadões para zuar e sair batendo". Ao apresentar esta pergunta "O que é dança para você?" no primeiro dia de aula no projeto, cada resposta reflete o dito, onde foi identificada uma reflexão que carece de conhecimentos do que realmente venha ser o dançar.

Porpino (2006) traz que o corpo conta história no dançar, tanto pode contar a história do seu povo ou de outros povos, carrega consigo identidades. Isto seria um interdito, ou seja, o que não é dito, mas silenciado (ASSIS et al., 2005), obscuro ao conhecimento popular, significados encobertos. Diante disso, vem a necessidade de ressignificação desses ditos sobre o dançar, levando aqueles alunos do PND a descobrirem o interdito da dança que nasce de uma experiência crítica, vivenciada em seus corpos.

\section{Dançando a dança}

$\mathrm{Na}$ descrição do processo, antes da prática em si, seja ela esporte, dança, lutas ou outras, os educandos e o educador no PND sentam-se em formato de roda, pois nesta forma todos podem se ver, além de oportunizar a troca de informações. Temos a roda inicial e a final, uma no início da aula e outra no final da prática, onde se configura como o momento onde o educando tem voz e vez, ou seja, a sua opinião e participação são valorizadas na construção e no prosseguimento das aulas, incentivando o desenvolvimento crítico. Também é na roda onde são sistematizados conteúdos, e vivenciados momentos de socialização. A Roda foi de suma importância nas nossas aulas de dança por essa potencialidade reflexiva, vindo acrescer num processo de ressignificação da dança no PND. A reflexão de Marques (1997) é pertinente quando diz que:

Quebrando-se o tabu de que "conversar não é dançar", poderíamos introduzir em nossas salas de aula momentos de reflexão, pesquisa, compara- 
ção, desconstrução das danças que apreciamos (ou não) e, assim, podermos agir crítica e corporalmente em função da compreensão, desconstrução e transformação de nossa sociedade. (MARQUES, 1997, p. 24).

Nesse sentido, foi desenvolvida uma proposta pedagógica inspirada nos temas desencadeadores de Ossona (1988). Refletimos no decorrer do plano de trabalho "O que é dança", "Por que dançar", "O que dançar", "Como dançar", "Para quem dançamos". Todas as brincadeiras, conversas em rodas, aprendizados de ritmos e conhecimentos sobre dança, estavam ligados a esses temas, ou seja, ao esclarecimento deles para uma provável ressignificação da dança para aqueles educandos.

Paralelamente a isso, temas transversais foram apontados e avaliados, estes temas envolvem questões sociais relativas à: Ética, Saúde, Orientação Sexual, Meio Ambiente, Pluralidade Cultural (BRASIL, 1998). Tudo isso discutido e refletido em roda e vivenciado no corpo do aluno por meio das atividades em dança. O que se quer ressaltar é a importância de construir formas operacionais de praticar e refletir sobre esses temas e valores, a partir da certeza de que apenas a prática das atividades e o discurso verbal do professor são insuficientes na sua transmissão e incorporação pelo estudante (BRASIL, 1998).

Na reflexão e ensino sobre Ética, as discussões incluíram uma dimensão pessoal no valor atribuído às atitudes certas ou erradas, positivas ou negativas, construtivas ou destrutivas ocorridas na sala de aula. Quando acontecia algo que dificultasse a socialização resolvíamos entre nós, principalmente na roda, colocávamos em pauta as atitudes positivas e negativas e eles tinham autonomia para julgar e chegarmos a um ponto que ajudasse a socialização e mesmo à conduta ética de cada um. Claro que às vezes muitas questões não se resolviam no mesmo dia, mas as atitudes negativas também davam suporte para mudanças no plano pedagógico para os outros dias.

No tocante à Saúde, reportamos a preocupação e a responsabilidade na valorização de conhecimentos relativos à construção da autoestima e da identidade pessoal, ao cuidado do corpo, à nutrição, à valorização dos vínculos afetivos e à negociação de atitudes e todas as implicações relativas à saúde da coletividade. Nesse sentido, algumas ressalvas foram feitas quanto ao tratamento dos valores e conceitos que circulam no ambiente sociocultural, veiculados principalmente pela mídia, e aos aspectos procedimentais como fonte de informações direta e necessariamente vinculada ao fazer corporal.

Tivemos também a preocupação, em nossas aulas, em trabalhar com a temática da Pluralidade Cultural em nosso objetivo de educar, assim como afirmam os PCNs - Parâmetros Curriculares Nacionais de Educação Física 
(1998), particularmente no Brasil, as danças, os esportes, as lutas, os jogos e as ginásticas, das mais variadas origens étnicas, sociais e regionais, compõem um vasto patrimônio cultural que deve ser valorizado, conhecido e desfrutado. $\mathrm{O}$ acesso a esse conhecimento contribui para a adoção de uma postura não preconceituosa e não discriminatória diante das manifestações e expressões dos diferentes grupos étnicos e sociais (religiosos, econômicos e de diferentes origens regionais) e das pessoas que deles fazem parte (BRASIL, 1998).

Além disso, acreditamos que o conhecimento oportunizado pela reflexão e vivência de uma pluralidade de manifestações culturais, evidenciadas em danças, inserem os indivíduos no universo da cultura, ampliando seus sentidos da existência e ratificando a educação.

Com o tema do Meio Ambiente, destacamos as interseções da Educação Física com este tema transversal, no que diz respeito ao cuidado de si mesmo, como um elemento integrante do meio ambiente, e à responsabilidade. $\mathrm{O}$ tema anual a ser trabalhado no PND no ano de 2008 foi Ecoesporte, no qual as aulas eram voltadas para uma reflexão e atribuição de valores sobre a importância de cuidar no nosso habitat e atitudes que façam colaborar com a manutenção do meio ambiente, por exemplo, foram plantadas árvores, reciclado lixo para produzir materiais esportivos e acessórios e vestimentas para dança. E era muito visível a cara de satisfação e entusiasmo dos educandos em manipularem nas aulas o material que eles produziram e olhar para as árvores que eles plantaram se sentindo participante de uma ação honrosa em favor do meio ambiente.

E repensando a Orientação Sexual, as práticas da cultura corporal de movimento se caracterizam, entre outros aspectos, por serem espaços de produção simbólica, de linguagens por meio das quais o homem se relaciona e se comunica com o outro e com sua própria cultura. Jogar, lutar e dançar pode representar, portanto, a possibilidade de expressar afetos e sentimentos, de explicitar desejos, de seduzir, de exibir-se. Essa comunicação ocorre dentro de certos padrões estabelecidos pela própria cultura corporal de movimento, o que envolve valores, normas, atitudes, conceitos e, inevitavelmente, preconceitos.

Para o jovem e o adolescente, as práticas da cultura corporal de movimento podem constituir-se num instrumento interessante de comunicação e construção de autoimagem, mas podem também, se certos cuidados não forem tomados, constituir-se num contexto ameaçador e desfavorável para essa mesma autoimagem. $\mathrm{O}$ ambiente sociocultural, permeado de valores preestabelecidos de beleza, estética corporal e gestual, eficiência e desempenho, se não for objeto de uma postura crítica e reflexiva, pode estabelecer padrões cruéis para a maioria da população, abrindo espaço para a tirania dos modelos de corpo e comportamento.

Nesse sentido, a valorização do estilo pessoal e do interesse de cada pessoa em aperfeiçoar-se em uma ou outra modalidade contribui para o cultivo da cul- 
tura corporal de movimento como possibilidade de se trabalhar a sociabilidade e convivência saudável. Sobre essa temática, uma das atividades trabalhadas com as turmas, foi a apreciação crítica de vídeos de desfiles de escolas de samba e a diversidade de linguagens corporais que se expressam nessas manifestações carnavalescas, em que crianças, passistas, malabaristas, ritmistas, ala das baianas compõem, cada um a seu modo, uma manifestação de intensa riqueza simbólica. Essa experiência trouxe um leque reflexivo sobre conceitos e preconceitos relativos à nudez, ao corpo do idoso e do jovem, e à diversidade de biótipos e formas de expressão corporal, outra vez que se pretende evitar uma abordagem apenas discursiva, mas sim buscar a construção de situações nas quais conceitos, preconceitos, valores e atitudes que tenham consequências efetivas, reais, concretas (BRASIL, 1998).

Nesse sentido, as atividades trabalhavam, além das questões sociais, elementos como musicalidade, noção espacial, temporal, locomoção, expressividade, entre outros, despertando para uma consciência corporal, para a respiração, para uma interação com os outros corpos dançantes e seu espaço de uma forma lúdica. Assim, podemos citar a atividade do Espelho em que os alunos são convidados em duplas a ficarem de frente um ao outro, onde um seria a imagem e o outro o espelho, este deveria imitar o que a imagem faria, com isso, eram colocadas músicas com ritmos diversos, tais como forró, salsa, rock, reggae, samba, entre outros, para eles explorarem em seus corpos e o espelho imitar, depois eram trocados os papéis e as duplas também.

Podemos citar também, na busca de ampliarmos os sentidos dos alunos no que se refere à dança, o trabalho com a improvisação explorando a criatividade. Para tanto brincávamos nas aulas com os ritmos, onde depois do aprendizado, por exemplo, de dois ritmos distintos, samba e frevo, eles tinham como tarefa, a partir da junção desses dois ritmos, a criação de um novo ritmo, "samfrevo", "frevosambando", que deveria ser apresentado a turma. Aulas como essas denotam a exploração de ritmos e a criação de maneiras próprias de se movimentar, ressignificando danças existentes e ampliando o sentido de educação,

Ainda sobre $o$ ato de ressignificar a dança evidenciando sentidos educativos, podemos citar os repertórios e práticas do mundo vivido das turmas, como formas de incluir a dança. Assim, ao propor a vivência do samba à turma, os alunos não pareciam confortáveis, pois gostariam de jogar futebol. Partindo dessa necessidade da turma, bolas foram entregues a eles, para que pudessem expressar o que sabiam fazer com elas, seguindo o ritmo musical. Assim surgiram embaixadinhas, chutes e outras movimentações que remetiam ao futebol, só que ao ritmo do samba e logo após essa exploração improvisada, foram inseridos passos do samba, juntando a experiência do futebol, ao universo do samba. 
Na roda eles testemunharam o quanto essa aula tinha sido importante para eles, assim como para o olhar da educadora, que uniu a experiência do futebol, com o ritmo do samba, possibilitando novas experiências para os alunos. O fruto desta aula foi uma composição coreográfica com a música "Partida de Futebol" do grupo Skank.

Acreditamos que buscar uma prática pedagógica com a dança mais coerente consiste em possibilitar ao indivíduo expressar-se criativamente, sem exclusões, tornando esta linguagem corporal transformadora e não reprodutora, como evidencia Gariba (2005).

Outra reflexão recorrente nas aulas em que a dança se faz presente e que amplia o sentido educativo, trata-se da questão do gênero. No intuito de trabalhar a ressignificação de que dança não é só para mulher, como foi apontada em muitas falas ao início do processo, trabalhamos em roda refletindo sobre história da dança e o papel e a importância do homem e suas danças em rituais sagrados. Além das danças sagradas, reportamos algumas culturas como a grega, por exemplo, em que a dança fazia parte não só de cerimônias religiosas, o culto à saúde e festas, mas do treinamento militar de guerreiros. Eles dançavam para alegrarem os deuses para que eles lhes dessem vitória nas guerras, uma boa colheita, entre outros motivos, como aponta Magalhães (2005).

Esses esclarecimentos faziam-se em roda e podíamos observar a reação de surpresa nos rostos dos alunos, por descobrirem os diferentes papéis assumidos pelos homens no contexto histórico da dança. Para ampliar essa reflexão, foi trabalhado com as turmas apreciações de vídeos para reflexão sobre o tema, como os filmes Billy Eliot, Dirty Dancing 2, Vem Dançar.

Assim, afirmamos a importância de se construir aulas que não evidenciem apenas a repetição e o aprendizado de passos das danças, mas formas de se refletir, de pensar sobre realidades que fazem parte do cotidiano dos alunos, ampliando os sentidos de existência desses sujeitos, por meio do envolvimento no universo da arte da dança, amplificando a educação nesses corpos.

\section{O Fim é apenas o Começo}

Abrem-se as cortinas para a última cena, o fim. E o que sempre se espera de um fim? Que ele responda às várias perguntas que surgem no decorrer da obra e que alcance as expectativas de um público e de toda uma equipe de artistas. Nem sempre isso é fato, mas é fato que houve ali uma interação da obra com seu público e estes não saíram do jeito que entraram, pois as portas 
da interpretação, da criação de sentidos foram abertas e algumas coisas, por mínimas que sejam permanecerão com eles, tatuadas em seus corpos. Segundo Oliveira $(1999$, p. 8$)$ "a arte é a eternidade conquistada por uma sensibilidade através do eco provocado noutras sensibilidades pelo seu espelho de infinitas dimensões". Outras pessoas dominam os códigos possíveis da arte como a música, a pintura, a escultura, o teatro, a dança, a literatura e etc., e conseguem conceber, criar a obra de arte. Outras, apesar de não serem criadoras, interagem com ela por meio de sua apreciação, descobrindo novas dimensões e sentidos. O artista conta com a cumplicidade do apreciador da arte, como afirma Oliveira (1999), em suas reflexões.

A cena final de todo esse andamento vem responder à problemática construída durante toda obra exposta aqui: a dança evidencia educação?

Retomando os significados atribuídos à dança do primeiro dia de aula, identificamos que para alguns a dança era somente para mulher - "dança é coisa de boiola" - pra outros a dança atua como um elemento de sedução - "danço pra conquistar as doidinhas" - elemento de agressividade - "danço nos pancadões para zoar e sair batendo" -, ou mesmo, bom para saúde, simplesmente legal, movimento pelo movimento, ou ela era somente aquele ritmo específico vivenciado em suas comunidades, tais como foram citados o funk e o forró, ou também, além de muitos desconhecerem seus significados.

De modo geral, os significados pautados naquelas respostas anteriores possibilitaram uma leitura da realidade daqueles alunos, onde observamos de imediato a falta de conhecimento e possíveis preconceitos sobre à prática da dança, ou seja, a falta de conhecimento do que viria a ser o dançar, o que nos deu subsídios para a elaboração dos conteúdos das aulas e a tentativa de construção de novos conceitos e significados.

Comparando essas respostas apresentadas no início do processo de apropriação do dançar, com as respostas apresentadas pelos alunos ao final do processo, confirmam a dança enquanto fonte educativa, como podemos observar nas respostas a seguir: 'Dançar é legal porque você se expressa, porque é muito bom, porque tem ritmos diferentes na dança, porque espanta os males, porque tem cultura na dança' (Educanda 12 anos), 'Porque tem ritmo cultural que todos devem aprender e devem ensinar aos outros sem ter preconceito com a dança, porque a dança é pra todos, para homem e mulher, para todos que querem aprender e ensinar' (Educando 10 anos). 'Eu gosto de dançar porque me expresso e faço e aprendo coisas novas, passos novos e me solto mais' (Educando 10 anos). 'A dança espanta os males, a pessoa se expressa na dança, ela é muito importante para mim, é importante para os artistas, a dança está em todos os lugares e é muito bom' (Educando 11 anos). 'Dançar é bom, a gente aprende a cultura, a dançar coisas diferentes, expressar tudo, dançar 
é importante' (Educando 12 anos), 'é importante para todos nós, é cultura e o frevo é muito legal' (Educando 11 anos), 'ela me fez ficar mais feliz e é muito importante para nossa vida' (Educanda 9 anos), 'é expressar o que tem dentro e falar com o corpo coisas que as palavras não falam, é cultura também e é uma arte' (Educando 16 anos).

Ao comparar as falas iniciais e finais sobre o que seria dança, percebemos que os sentidos atribuídos à dança foram amplificados, tanto na percepção do envolvimento das turmas nas aulas, a partir das várias atividades propostas, mas também em suas respostas sobre o que é dança, quando a maioria das respostas continha a palavra cultura, visto que o homem é um ser construído culturalmente e a dança evidencia essas construções culturais dos diferentes povos, o que pode permitir um senso crítico dessas diferentes realidades, além de seu conhecimento expresso em cada gesto dançante.

Nesse sentido, acreditamos ser essa uma das tarefas da educação, a inserção dos indivíduos no universo da cultura e da arte, ampliando os sentidos da existência e do encontro com o outro. Observou-se, portanto, nas respostas, a importância atribuída a essa arte, que trabalha com a expressão, que é linguagem do corpo e que, portanto, comunica saberes diversos, os quais esses alunos puderam compreender e também comunicar.

\section{REFERÊNCIAS}

ASSIS, M.; CORREIA, A.; TEVES, N. O Dito e o Interdito: análises das formações discursivas produzidas pela mídia impressa pelo papel atribuído à dança em projetos sociais no Rio de Janeiro. Revista Brasileira de Ciências do Esporte, Campinas, v. 26, n. 2, p. 101-115, jan. 2005.

BRASIL. Secretaria de Educação Fundamental. Parâmetros Curriculares Nacionais. Brasília: MEC/SEF, 1998.

FEITOSA, C. Por que a filosofia esqueceu a dança? In: BARRENECHEA, M. A.; CASANOVA, M. A.; DIAS, R.; FEITOSA, C. (Org.). Assim falou Nietzsche III: para uma filosofia do futuro. Rio de Janeiro: 7 Letras, 2009.

GARIBA, C. M. S. Dança Escolar: uma linguagem possível na Educação Física. Revista Digital - Buenos Aires, año 10, n. 85, jun. 2005.

LABAN, R. Dominio do movimento. São Paulo: Summus, 1978.

LABAN, R. Dança educativa moderna. Trad. Maria da Conceição P. de Campos. São Paulo: Ícone, 1990. 
MAGALHÃES, M. C. A dança e sua característica sagrada. Existência e Arte- Revista Eletrônica do Grupo PET - Ciências Humanas, Estética e Artes da Universidade Federal de São João Del-Rei, ano I, n. I, janeiro a dezembro de 2005. Disponível em: <http:// www.miniweb.com.br/Artes/artigos/danca.pdf $>$. Acesso em: 22 jun. 2009.

MARQUES, I. Dançando na Escola. Motriz, v. 3, n. 1, jun. 1997.

MARTINS, J. A pesquisa qualitativa em Psicologia: fundamento e recursos básicos. São Paulo: Centauro, 2005.

MEDEIROS, R. M. N. Uma educação tecida no corpo. 2. ed. São Paulo: Annablume, 2016.

MERLEAU-PONTY, M. Fenomenologia da percepção. São Paulo: Martins Fontes, 1999.

MORIN, E. Os sete saberes necessários à educação do futuro. 4. ed. São Paulo: Cortez; Brasília: Unesco. 2001.

NÓBREGA, T. P. Para uma Teoria da Corporeidade: um diálogo com Merleau-Ponty e o pensamento complexo. 1999. Tese (Doutorado em Educação) - Universidade Metodista de Piracicaba, Programa de Pós-Graduação em Educação. Piracicaba-SP, 1999.

NÓBREGA, T. P. Uma fenomenologia do corpo. São Paulo: Editora Livraria da Física, 2010.

OLIVEIRA, C. B. de. Arte literária: Portugal/Brasil. São Paulo: Editora Moderna, 1999. OSSONA, P. A educação pela dança. São Paulo: Summus Editorial, 1988.

PORPINO, K. de O. Dança é educação: interfaces entre corporeidade e estética. Natal-RN: EDUFRN - Editora da UFRN, 2006.

STRAZZACAPPA, M. A Educação e a fábrica de corpos: a dança na escola. Cadernos Cedes, ano XXI, n. 53, abril/2001.

Texto recebido em 29 de agosto de 2017. Texto aprovado em 27 de dezembro de 2017. 